\section{A) Check for updates}

Cite this: Dalton Trans., 2019, 48 3369

Received 28th September 2018, Accepted 12th February 2019

DOI: $10.1039 / \mathrm{c} 8 \mathrm{dt} 03912 \mathrm{~g}$

rsc.li/dalton

\title{
Non-conventional synthesis and photophysical studies of platinum(II) complexes with methylene bridged 2,2'-dipyridylamine derivatives $\dagger$
}

\author{
Evgeny Bulatov (D) and Matti Haukka (D) *
}

\begin{abstract}
Methylene bridged 2,2'-dipyridylamine (dpa) derivatives and their metal complexes possess outstanding properties due to their inherent structural flexibility. Synthesis of such complexes typically involves derivatization of dpa followed by coordination on metals, and may not always be very efficient. In this work, an alternative synthetic approach, involving the derivatization step after - rather than prior to - coordination of dpa on metal center, is proposed and applied to synthesis of a number of platinum(॥) complexes with substituted benzyldi(2-pyridyl)amines. Comparison with the more conventional synthetic route reveals greater efficiency and versatility of the proposed approach. The obtained complexes are not luminescent in solution at room temperature, but display blue phosphorescence emission (ca. $415 \mathrm{~nm}$ ) with the lifetimes of $\mu$ s order in glassy matrix at $77 \mathrm{~K}$, with additional green $(c a .485 \mathrm{~nm})$ and relatively long living $(\tau=$ $3.7 \mathrm{~ms}$ ) emission in the case of iodine substituted derivative.
\end{abstract}

\section{Introduction}

Profound flexibility and chelating capabilities of 2,2'-dipyridylamine (di(2-pyridyl)amine, dpa) have stimulated excessive studies of its coordination chemistry, ${ }^{1}$ as well as incorporation of this moiety as a metal binding center into more complex organic materials. ${ }^{2}$ The latter is usually achieved by connecting dpa with an organic fragment via the amino nitrogen atom, and the resulting derivatives can be conjugated or non-conjugated (Scheme 1). Such organic molecules can be applicable in organic light emitting devices, ${ }^{3-6}$ while their ability to bind various transition metals through the dpa moiety allows their use as various luminescent sensors. ${ }^{7,8}$ Since dpa complexes of platinum(II) and palladium(II) have been found to possess cytotoxic activities comparable to or higher than cisplatin, ${ }^{9-11}$ complexes with dpa derivatives have been considered as potential antitumor agents. ${ }^{12-15}$

Variety of conjugated derivatives and their metal complexes, in which the amino nitrogen atom of dpa is directly connected with an aromatic system, have been synthesized and studied by the group of S. Wang ${ }^{6,16-18}$ and more recently by K.-J. Wei

Department of Chemistry, University of Jyväskylä, P.O. Box 35, FI-40014 Jyväskylä, Finland. E-mail: matti.o.haukka@jyu.fi

$\dagger$ Electronic supplementary information (ESI) available: Additional details and discussion on syntheses and side products, photocyclization of 1, phosphorescence excitation and variable temperature time resolved emission spectra of [7-10] $\cdot \mathrm{Br}_{2},{ }^{1} \mathrm{H}$ NMR spectra of all compounds, and crystallographic data. CCDC 1868987-1868999. For ESI and crystallographic data in CIF or other electronic format see DOI: $10.1039 / \mathrm{c} 8 \mathrm{dt} 03912 \mathrm{~g}$ et al. ${ }^{19-21}$ Despite their attractive luminescent properties, real life application of such materials can be hindered by the complicated synthesis, which often involves transition metal catalyzed cross-coupling reactions (Scheme 1, left).

Non-conjugated derivatives, in which dpa moiety is connected with an aliphatic carbon atom, represent another family of dpa based materials. The number of studies on alkylsubstituted di(2-pyridyl)amines is rather limited, ${ }^{12,13}$ whereas methylene bridged aromatic derivatives receive more attention recently (Scheme 1, right). Inherent flexibility provided by the methylene linker not only expands the range of possibilities for various supramolecular motifs in solid state, as studied by L. Lindoy et al. ${ }^{22-24}$ but also allows for non-trivial reactivity ${ }^{25}$ and luminescent properties ${ }^{26,27}$ of these compounds and their metal complexes. Compared to their conjugated counterparts, methylene bridged dpa derivatives are much easier to synthesize from dpa and corresponding halides via nucleophilic substitution reaction in presence of a base. Corresponding

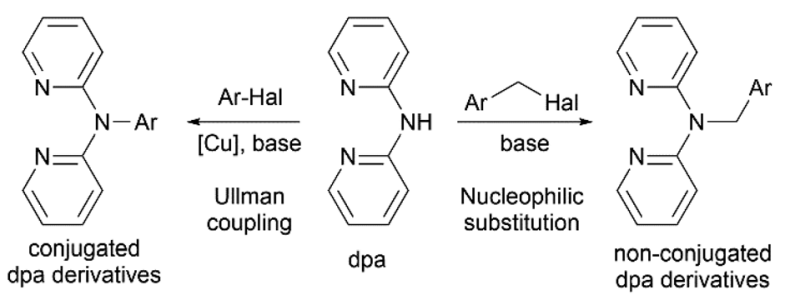

Scheme 1 Conjugated and non-conjugated dpa derivatives and their syntheses. 
metal complexes can be then obtained by coordinating the dpa fragment on metals using conventional methods of coordination chemistry.

In this work we demonstrated, that the aforementioned conventional synthesis of methylene bridged dpa derivatives from dpa and corresponding halides does not always provide sufficient yields, and proposed an alternative synthetic approach, which involves the derivatization step after - rather than prior to - coordination of dpa on metal center. This approach makes the nucleophilic substitution reaction easier and more tolerant to various substituents in the halides, and allows more efficient synthesis of series of dpa based metal complexes with various organic backbones. Efficiency and versatility of the proposed synthetic approach were demonstrated on synthesis of series of substituted benzyldi(2-pyridyl)amines and their platinum(II) complexes. In addition, the products were structurally characterized and their photophysical properties were investigated.

\section{Results and discussion}

\section{Synthesis}

As mentioned above, the methylene bridged dpa derivatives are usually obtained by nucleophilic attack of the amino nitrogen atom of dpa on benzyl halides in presence of a base (Scheme 2a). However, several side processes can diminish the reaction yield; for example, the reported yields of benzyldi(2pyridyl)amine vary from as high as $82 \%{ }^{28}$ to as low as $16 \% .^{22}$

a)

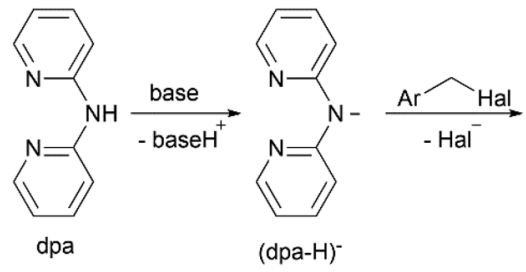

b)
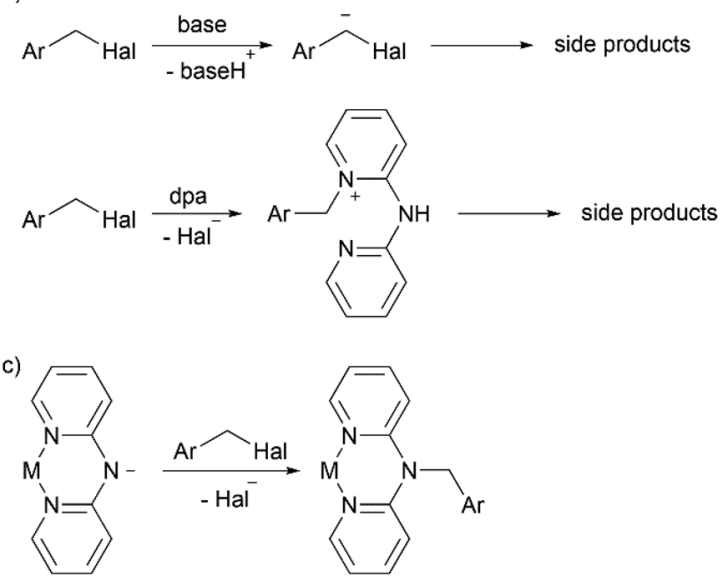

Scheme 2 Reaction between dpa and benzyl halides: (a) target reaction, (b) undesired side reactions, (c) proposed reaction with (dpa-H) complexes.
As we demonstrated in this work, the reaction becomes particularly problematic, when an electron withdrawing group is introduced in the phenyl ring (the same trend can also be found in another recent publication ${ }^{29}$ ). In such case, the methylene group can be easier deprotonated by the base due to stabilization of the resulting anion, leading to undesired side reactions. Additionally, benzylation of the pyridine nitrogen atoms instead of the amino nitrogen atom may take place (Scheme 2b).

Inspired by reports of various transition metal complexes containing deprotonated di(2-pyridyl)amide $(\text { dpa- } \mathrm{H})^{-}$ ligands, ${ }^{30-33}$ we suggested that use of such complexes in the benzylation reaction (Scheme $2 \mathrm{c}$ ) could suppress the aforementioned undesired side processes. Thus, use of a base would be unnecessary in the reaction since the amino nitrogen atom of dpa is already deprotonated. Therefore, deprotonation of the methylene group of the benzyl halide would be avoided. The pyridine nitrogen atoms would be protected from benzylation by metal center. Moreover, such approach would allow more efficient synthesis of complexes of a particular metal with various non-conjugated dpa-derived ligands, which is a common research practice (for examples, see ref. 22, 23, 25, 27 and 29). Using the proposed method, such series of complexes could be easily obtained in one step from the $(\mathrm{dpa}-\mathrm{H})^{-}$containing complex and corresponding halides. The approach of derivatization of coordinated ligands has been applied, for example, to synthesis of various bipyridine and terpyridine complexes of ruthenium(II) and named as "Organic chemistry of coordination compounds" 34 or "Chemistry on the complex". 35

We decided to test the proposed approach on synthesis of substituted benzyldi(2-pyridyl)amines 1-3 with substituents $\mathrm{R}=\mathrm{H}$, I, and $\mathrm{NO}_{2}$ in ortho-position of the phenyl ring as representatives of methylene bridged dpa derivatives with various electronic properties of the substituents. Metal center was chosen to be platinum(II), which is often used in development of phosphorescent materials due to its strong spin-orbit coupling; ${ }^{36}$ complexes of platinum(II) with dpa-based ligands are also considered as potential anticancer agents. ${ }^{12-15}$ In addition, synthesis of $\left[\mathrm{Pt}(\mathrm{dpa}-\mathrm{H})_{2}\right]^{33}$ and methylation of a structurally related bis(imidoylamidinate)platinum(II) complex $\left[\mathrm{Pt}\{\mathrm{NH}=\mathrm{C}(\mathrm{Ph})-\mathrm{NC}(\mathrm{Ph})=\mathrm{NPh}\}_{2}\right],{ }^{37}$ which can be seen as prototype for the dpa benzylation reaction, have been published previously (Scheme 3).

The target benzyldi(2-pyridyl)amines 1-3 and platinum(II) complexes 4-10 were synthesized using both conventional (benzylation prior to coordination) and alternative (benzylation after coordination) approaches (Scheme 4). Below particular details of syntheses are discussed in detail and comparison between the two approaches is presented.

Conventional synthetic route. Benzyldi(2-pyridyl)amines 1 and 2 were synthesized by adapting published procedure ${ }^{22}$ via nucleophilic attack of dpa on corresponding benzyl bromides in presence of sodium hydroxide. However, synthesis of 3 using the same technique failed due to enhanced methylene group reactivity (for discussion and identification of side pro- 
a)

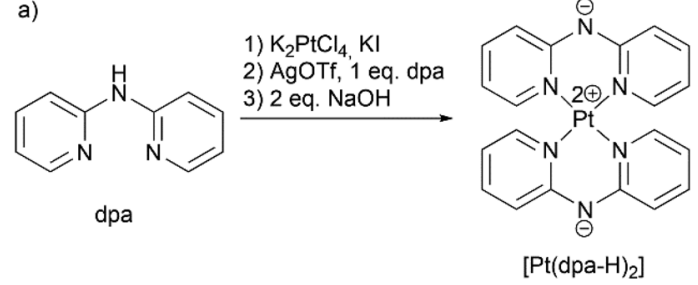

b)<smiles></smiles>

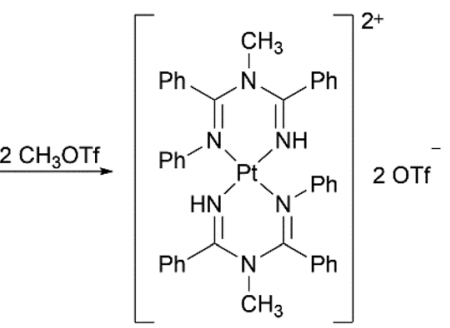

Scheme 3 Known reactions of platinum(II) complexes, which inspired this work: (a) synthesis of $\left[\mathrm{Pt}(\mathrm{dpa}-\mathrm{H})_{2}\right],{ }^{23}$ (b) methylation of $[\mathrm{Pt}\{\mathrm{NH}=\mathrm{C}$ $\left.(\mathrm{Ph})-\mathrm{NC}(\mathrm{Ph})=\mathrm{NPh}\}_{2}\right]^{26}$

ducts, see section $\mathrm{S} 1$ in the ESI $\dagger$ ), and consequently two step synthesis $^{38}$ implying water-free conditions and sodium hydride as a base was performed.

The obtained compounds were then coordinated on platinum(II) by adapting known procedures ${ }^{33}$ in two steps. First, diiodide complexes 4-6 were obtained by reacting $\mathrm{K}_{2} \mathrm{PtCl}_{4}$ with one equivalent of 1-3 and excess of $\mathrm{KI}$ in water. The homoleptic complexes [7-9].(OTf $)_{2}$ were then obtained by reacting the diiodide complexes with another equivalent of the corresponding ligand 1-3 in acetonitrile in presence of silver(I) triflate (Scheme 4 top).

Alternative synthetic route. Neutral complex $\left[\mathrm{Pt}(\mathrm{dpa}-\mathrm{H})_{2}\right]$ was synthesized using published procedure. ${ }^{33}$ Reaction of this complex with corresponding benzyl bromides afforded target homoleptic complexes [7-9] $\cdot \mathbf{B r}_{\mathbf{2}}$. Additionally, complex [10] $\mathbf{B r}_{\mathbf{2}}$ containing 2-cyanobenzyldi(2-pyridyl)amine ligands was synthesized with ease using this method (Scheme 4 bottom).

Yields of the two syntheses are compared in Table 1. Clearly, the alternative synthetic route provides higher overall yields of the homoleptic complexes 7-10 due to lower number and higher yields of the individual steps. In addition, introduction of the electron withdrawing groups in the benzyl moiety does not drastically affect the yields, in contrast with the conventional synthesis. Lesser reaction steps are also important for a practical synthesis. The conventional method required 9 steps to synthesize complexes [7-9]-(OTf) $)_{2}$ (3 reaction steps per complex), and many of them required individual approach due to variable properties (such as solubility and crystallizability) of the derivatives. On the other hand, starting from $\left[\mathrm{Pt}(\mathrm{dpa}-\mathrm{H})_{2}\right]$, the alternative method took only 3 steps to synthesize these complexes as bromides using very similar

Table 1 Yields of complexes 7-10 in the two synthetic approaches

\begin{tabular}{lll}
\hline & \multicolumn{2}{c}{ Overall yield (yields of individual stages), \% } \\
\cline { 2 - 3 } Complex & Conventional synthesis $^{a}$ & Alternative synthesis $^{b}$ \\
\hline $\mathbf{7}$ & $3(26 \times 82 \times 14)$ & $37(38 \times 97)$ \\
$\mathbf{8}$ & $13(44 \times 48 \times 61)$ & $24(38 \times 64)$ \\
$\mathbf{9}$ & $0.3(9 \times 20 \times 15)$ & $32(38 \times 85)$ \\
$\mathbf{1 0}$ & - & $30(38 \times 79)$
\end{tabular}

${ }^{a}$ Overall yields were obtained by multiplication of the individual yields of the corresponding stages in the following order: dpa $\rightarrow$ ligands (1-3), ligands (1-3) $\rightarrow$ diiodide complexes (4-6), and diiodide complexes (4-6) $\rightarrow$ homoleptic complexes ([7-9]-(OTf) $)_{2}$ ). ${ }^{b}$ Overall yields were obtained by multiplication of the yields of the corresponding individual stages in the following order: dpa $\rightarrow\left[\mathrm{Pt}(\mathrm{dpa}-\mathrm{H})_{2}\right],[\mathrm{Pt}(\mathrm{dpa}-$ $\left.\mathrm{H})_{2}\right] \rightarrow$ homoleptic complexes $\left([\mathbf{7 - 1 0}] \cdot \mathbf{B r}_{2}\right)$.

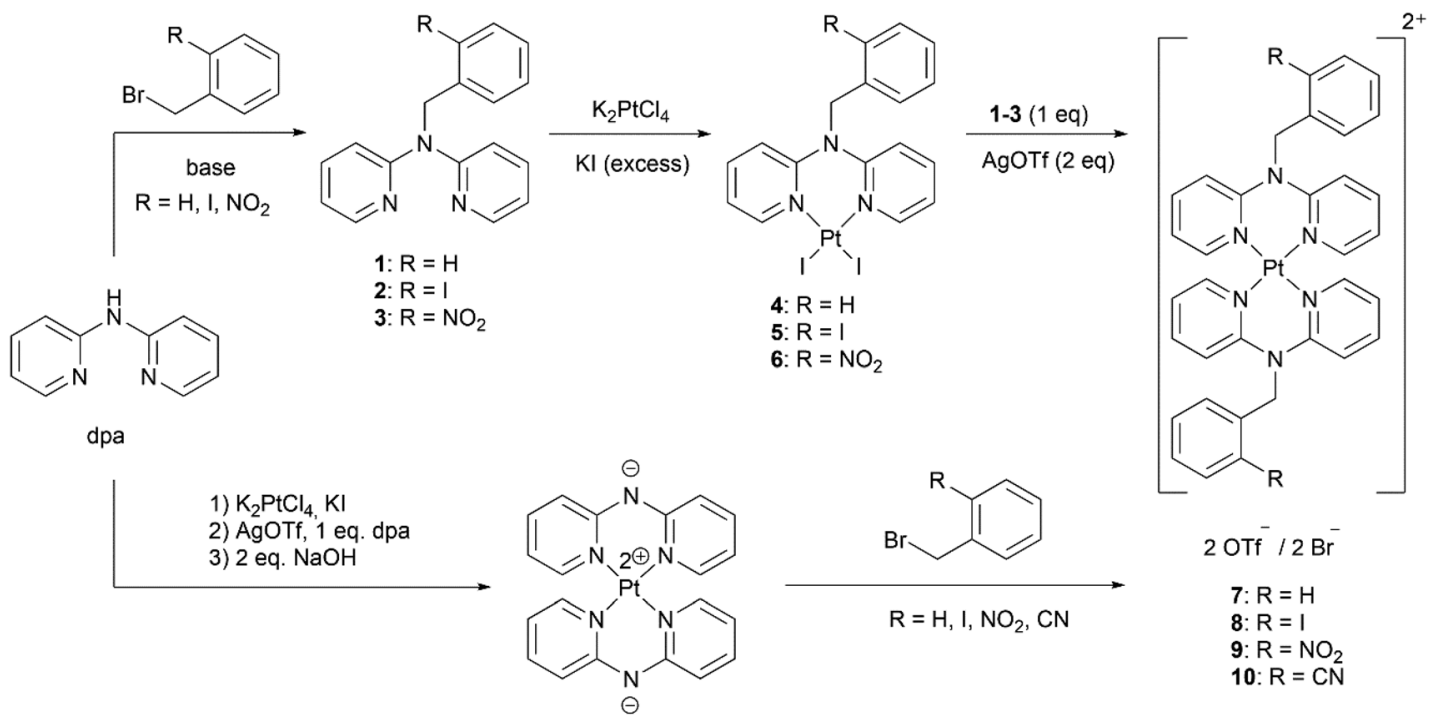

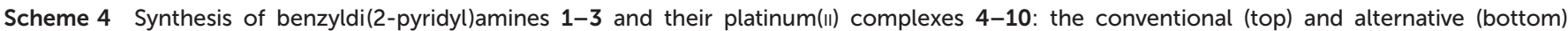
approaches. 
reaction conditions and workup. Moreover, any other derivative could be obtained just in one simple step using this method, as demonstrated by synthesis of $[\mathbf{1 0}] \cdot \mathbf{B r}_{2}$.

These results demonstrate, that the alternative approach can be very convenient in synthesis of platinum(II) complexes with various methylene bridged dpa ligands. Moreover, even though separate tests were not performed, we believe that this approach can also be utilized for synthesis of platinum(II) complexes with only one methylene bridged dpa ligand. This suggestion is supported by the obtained side product dibromo(2-cyanobenzyldi(2-pyridyl)amine)platinum(II) (S4) in synthesis of $[\mathbf{1 0}] \cdot \mathbf{B r}_{\mathbf{2}}$ (see section S2 in the ESI† for details).

\section{Characterization of the products}

In this section, crystal structures and general ${ }^{1} \mathrm{H}$ NMR spectral features of all the obtained benzyldi(2-pyridyl)amines 1-3 and platinum(II) complexes 4-10 are discussed.

Benzyldi(2-pyridyl)amines 1 and 2 crystallize in monoclinic space group $P 2_{1} / n$, and 3 crystallizes in triclinic $P \overline{1}$ space group. In crystal structure of $\mathbf{1}$ pyridyl rings are in cis-trans conformation, whereas substituted derivatives 2 and 3 possess cis-cis conformation (using notation from ref. 1), and orientation of the phenyl ring in $\mathbf{2}$ and $\mathbf{3}$ is such that the substituents are turned outward from the pyridyl rings (Fig. 1). Halogen bond $\mathrm{N}_{\text {py }} \cdots \mathrm{I}\left(d\left(\mathrm{~N}_{\text {py }} \cdots \mathrm{I}\right)=3.29 \AA, \angle\left(\mathrm{N}_{\text {py }} \cdots \mathrm{I}-\mathrm{C}\right)=166^{\circ}\right)$ in crystal structure of 2 accounts for formation of the halogen bonded dimers (Fig. 2).

${ }^{1} \mathrm{H}$ NMR spectra of 1-3 possess a number of multiplet signals in aromatic area (8.3-6.8 ppm) corresponding to the hydrogen atoms of pyridyl and phenyl rings, and one singlet signal at 5.8-5.4 ppm corresponding to the methylene hydrogen atoms.

Diiodide complexes 4 and 6 crystallize in triclinic $P \overline{1}$ space group, whereas 5 crystallizes in monoclinic space group $P 2_{1} / n$. In all complexes, the metal center is coordinated by the dpa derived ligands via pyridine nitrogen atoms $(d(\mathrm{Pt}-\mathrm{N})=$ 2.03-2.06 $\left.\AA, \angle(\mathrm{N}-\mathrm{Pt}-\mathrm{N})=84.9-85.3^{\circ}\right)$, forming six-membered chelate rings in boat conformation, with 50.6-53.5 $5^{\circ}$ dihedral angles between the pyridine planes. Such coordination is common for platinum(II) complexes with methylene bridged dpa derivatives. ${ }^{12,13}$ Two iodide ligands complete slightly distorted square planar configuration of the platinum metal centers with Pt-I bond lengths 2.58-2.60 А and I-Pt-I angles 91.0-91.9 . In crystal structure of 5 , the phenyl iodine atom I3 is oriented towards platinum center, with Pt...I distance of $3.94 \AA$. In 6, however, the nitro group is oriented away from platinum center (Fig. 3).

${ }^{1} \mathrm{H}$ NMR spectra of 4-6 show downfielded (9.4-9.5 ppm) aromatic signal possessing characteristic broadened satellites due to splitting from ${ }^{195} \mathrm{Pt}$ nucleus $\left({ }^{3} J_{\mathrm{H}-\mathrm{Pt}}=48-64 \mathrm{~Hz}\right)$, which can therefore be assigned to pyridine hydrogen atoms in $6^{\text {th }}$ position. The other aromatic and methylene proton signals of the complexes resemble those of the corresponding ligands.

Homoleptic complexes 7-10 form crystals of different morphologies depending on counter ion. In order to obtain high quality crystals, 7, 8, 10 were crystallized as triflates, whereas $\mathbf{9}$ was crystallized as a bromide. $[7,8] \cdot(\mathbf{O T f})_{2}$ and $[\mathbf{9}] \cdot \mathbf{B r}_{2}$ crystallize in monoclinic space group $C 2 / c\left([\mathbf{9}] \cdot \mathbf{B r}_{2}\right.$ was crystallized as tetrahydrate), and $[\mathbf{1 0}] \cdot(\mathbf{O T f})_{2}$ crystallizes in triclinic $P \overline{1}$ space group as dihydrate. Complexes 7-10 are centrosymmetric in solid state with platinum atoms at the inversion centers. Thus, asymmetric units in 7-10 contain platinum center with one

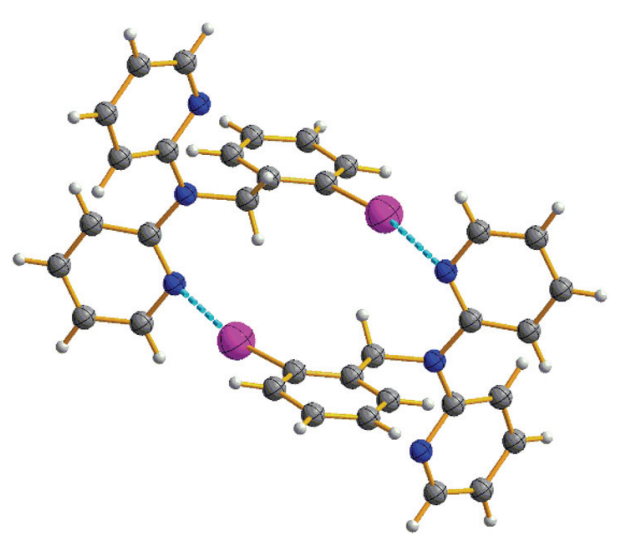

Fig. 2 Halogen bonded dimers of 2.
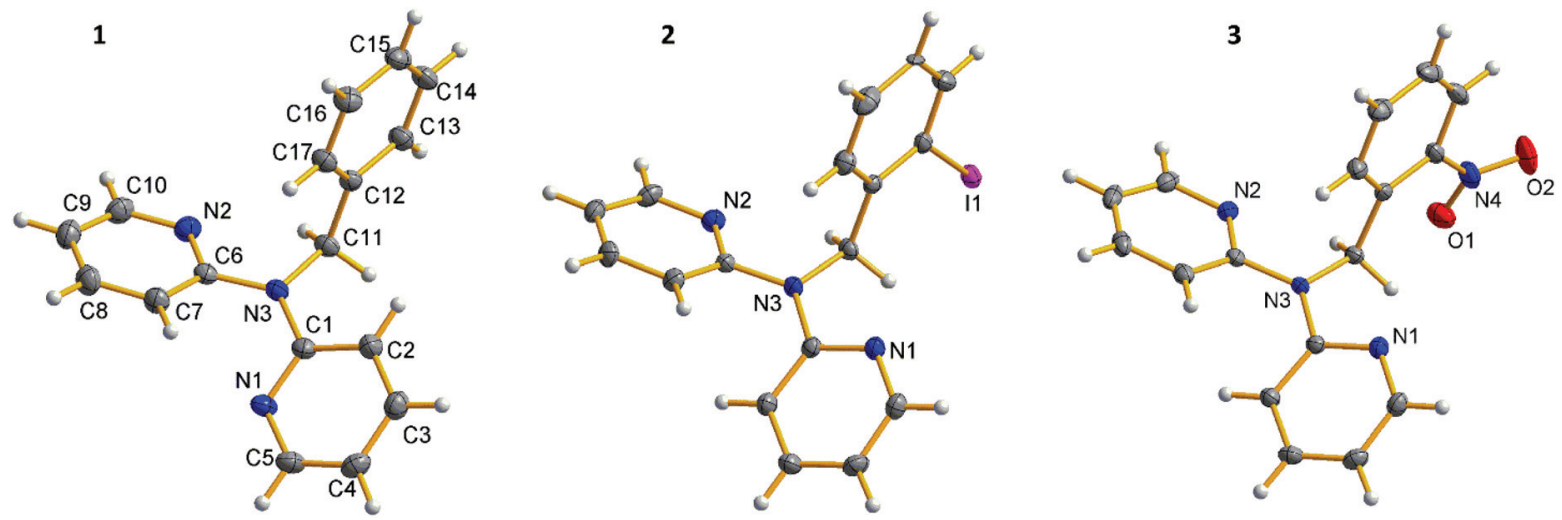

Fig. 1 Crystal structures of 1-3. 

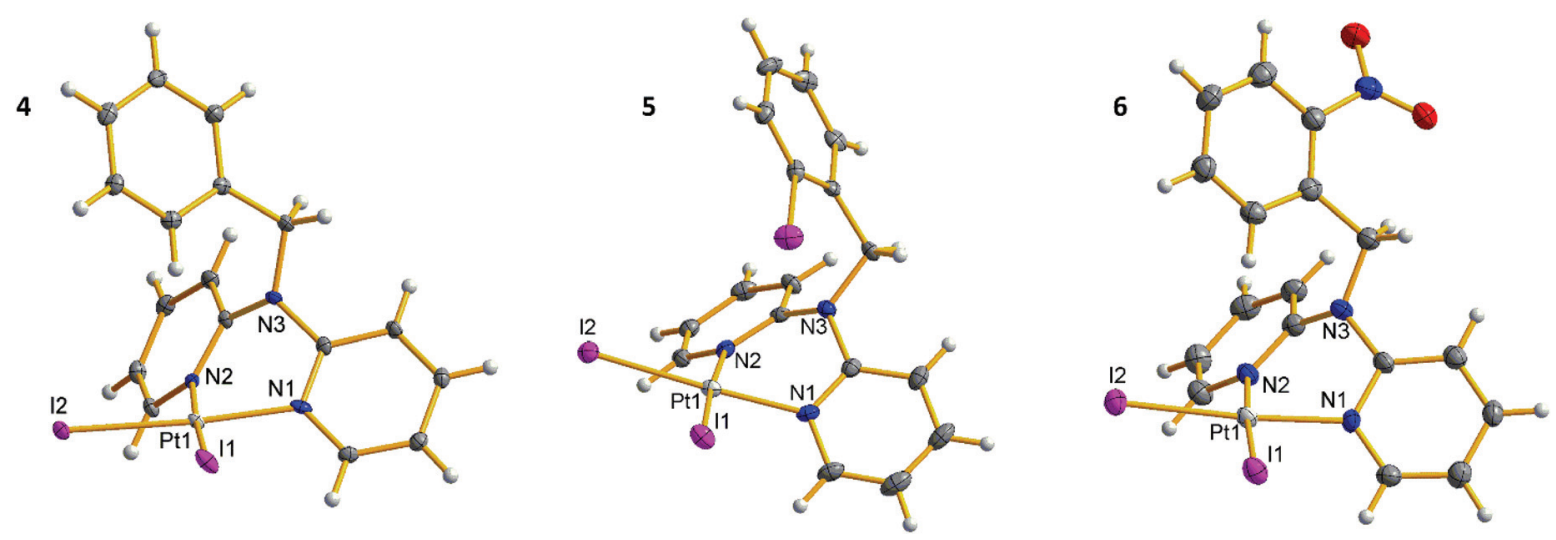

Fig. 3 Crystal structures of 4-6.

ligand and one counter ion (and two and one water molecule in [9]·Br ${ }_{2}$ and [10].(OTf $)_{2}$ accordingly). Platinum centers possess square planar configuration with $\mathrm{Pt}-\mathrm{N}$ bond lengths 2.01-2.02 and chelate N1-Pt-N2 angles $85.4-86.4^{\circ}$, and the six-membered chelate rings adopt boat conformation (dihedral angles between the pyridine planes $46.0-55.7^{\circ}$ ). Orientation of the phenyl ring in [8].(OTf $)_{2}$ is disordered between two positions: with iodine atom directed towards and away from platinum center. Nitro group in [9] $\cdot \mathbf{B r}_{2}$ and cyano group in [10].(OTf $)_{2}$ are oriented towards platinum center with $d(\mathrm{O} 2 \cdots \mathrm{Pt})=3.27 \AA$ in the former and $d(\mathrm{~N} 4 \cdots \mathrm{Pt})=3.39 \AA$ in the latter (Fig. 4).

${ }^{1} \mathrm{H}$ NMR spectra of 7-10 show that hydrogen atoms of the two ligands are pairwise magnetically equivalent in all complexes. Signals of the pyridine hydrogen atoms in $6^{\text {th }}$ position are shifted upfield compared with the precursor diiodide complexes, and the satellites due to splitting from ${ }^{195} \mathrm{Pt}$ can barely be observed among the other aromatic signals.

\section{Optical spectroscopy}

Absorption spectra of 1-3 in methanol are presented in Fig. 5, and their features are summarized in Table S1 in the ESI. $\dagger$ The lowest energy absorption bands of the ligands can be assigned to the $\pi-\pi^{*}$ transitions within dpa moiety. ${ }^{27}$ Studies of photophysical properties of benzyldi(2-pyridyl)amines 1-3 are complicated due to their ability to undergo photocyclization in solution. ${ }^{39,40}$ While this process is slow enough to allow the measurement of absorption spectra, strong luminescence of the products and intermediates of the photocyclization interferes with the emission spectra of 1-3 in solution (for details, see section S3 in the ESI $\dagger$ ). For this reason, studies of luminescent properties of the ligands were not included in this work. We have previously studied luminescent behavior of dpa hydrochloride, in which protonation of the pyridine nitrogen atoms suppresses the reaction of photocyclization in solution. ${ }^{41}$ Analogous studies on luminescence of ligands 1-3 and other methylene bridged dpa derivatives are underway in our research group.

Absorption and photoluminescence emission spectra of [7-10] $\cdot \mathbf{B r}_{2}$ are presented in Fig. 6 and summarized in Table 2.
The lowest energy absorption bands of the complexes and the ligands possess similar wavelengths $\left(\lambda_{\max } \approx 310 \mathrm{~nm}\right.$ and $305 \mathrm{~nm}$ accordingly) and extinction coefficients $(\varepsilon \approx(13-16) \times$ $\left.10^{3} \mathrm{l} \mathrm{mol}^{-1} \mathrm{~cm}^{-1}\right)$. The latter observation may indicate change in the nature of the lowest electronic transition upon coordination of the ligands to the platinum center. Complexes [7-10] $\cdot \mathbf{B r}_{2}$ contain two ligands per molecule, and in the case of pure intraligand $\pi-\pi^{*}$ transitions approximately twice higher absorptivity would be expected for the complexes compared to the ligands. ${ }^{42}$ In addition, previously published computational studies on platinum(II) complexes with dpa derived ligands revealed a significant contribution of the metal center in the frontier molecular orbitals. ${ }^{15}$ Therefore, the low energy absorptions in [7-10] $\cdot \mathbf{B r}_{2}$ are assigned to $\pi-\pi^{*}$ transitions within dpa moiety with an additional metal-to ligand charge transfer contribution.\$

Solutions of [7-10] $\cdot \mathbf{B r}_{2}$ are not luminescent in methanol at room temperature. Quenching of luminescence of platinum(II) complexes is usually attributed to thermal population of relatively low lying metal centred excited states, leading to distortion of coordination geometry and consequent non-radiative relaxation. ${ }^{43}$ In order to observe the emission, solutions of the complexes in methanol/ethanol mixture $(1: 4, \mathrm{v} / \mathrm{v})^{44}$ were cooled down to $80 \mathrm{~K}$ to form semi-rigid transparent glasses.

Emission properties of complexes $[\mathbf{7 - 1 0}] \cdot \mathbf{B r}_{2}$ share some common features. Thus, all complexes display emission bands with $\lambda_{\max }=407-425 \mathrm{~nm}$, and a good match was observed between the absorption (Fig. 6) and excitation (Fig. S6 in the ESI $\dagger$ ) spectra. Analysis of the time-resolved spectra (see section $\mathrm{S} 4$ in the ESI $\dagger$ ) reveals biexponential decays of these emission bands. In all cases, the initial fast decay is followed by the slower one, characterized by lifetimes $\tau_{1}$ and $\tau_{2}$ accordingly in Table 2. The obtained values allow assignment of the observed emission to phosphorescence.

However, significant differences are apparent from the

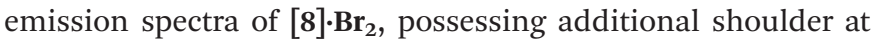

$¥$ This assignment is also supported by the preliminary computational DFT studies on [8] $\cdot \mathbf{B r}_{2}$ (to be presented in the follow-up publication). 

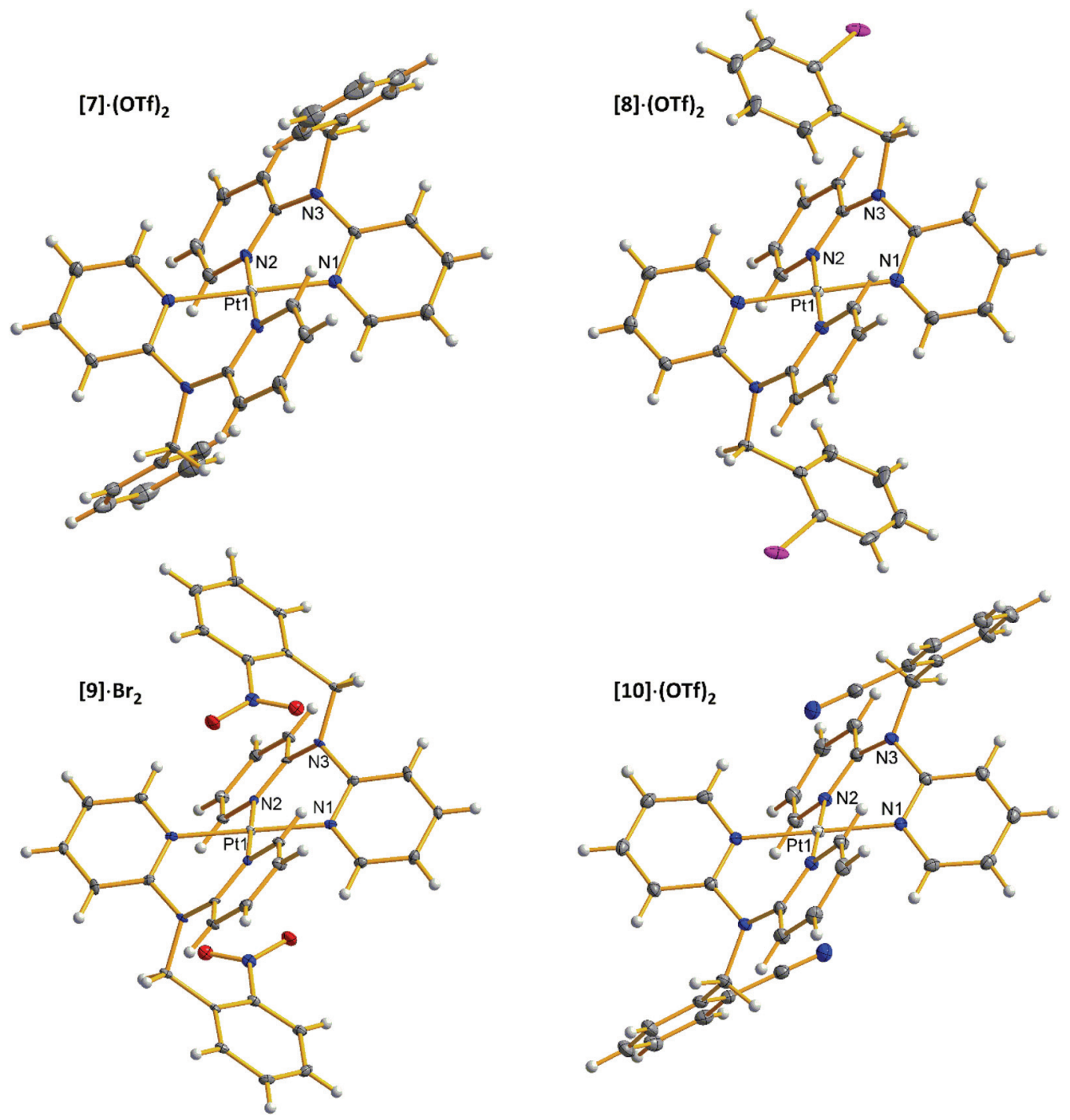

Fig. 4 Crystal structures of 7-10. Anions and solvent molecules are omitted for clarity.

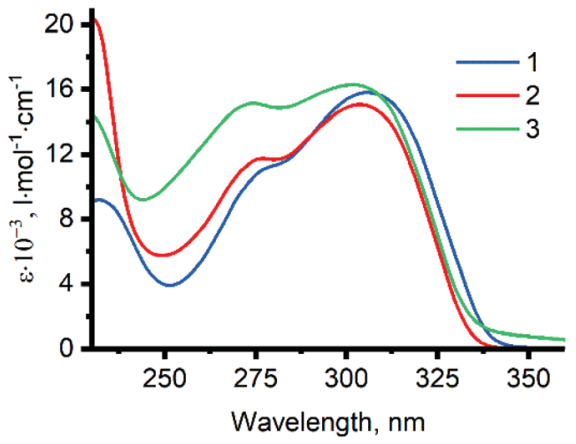

Fig. 5 Absorption spectra of ligands 1-3 $(C=50 \mu \mathrm{M})$ in methanol.

$\lambda_{\max } \approx 475 \mathrm{~nm}$, and [10]·Br $\mathbf{B r}_{2}$, possessing additional peaks at $\lambda_{\max }=448$ and $480 \mathrm{~nm}$. While in the latter case the emission spectrum only slightly changes with time at $80 \mathrm{~K}$ (Fig. S7 in the ESI $\dagger$ ), the two emission bands of $[8] \cdot \mathbf{B r}_{2}$ at $\lambda_{\max }=417$ and
$470 / 500 \mathrm{~nm}$ possess strikingly different lifetimes of $39 \mu \mathrm{s}$ and $3.7 \mathrm{~ms}$ accordingly. Time dependence of emission spectrum of [8] $\cdot \mathbf{B r}_{2}$ is illustrated on Fig. 7 and Fig. S8 in the ESI. $\dagger$

At higher temperatures small red shift of all of the emission peaks is accompanied by decrease of lifetimes and emission intensity until complete disappearance at 140-150 K. Temperature dependencies of the observed rate constants reveal plateaus in most of cases at temperatures close to $80 \mathrm{~K}$, indicating that the temperature-dependent non-radiative processes are suppressed at this point. ${ }^{45}$

In addition, [7,9] $\cdot \mathbf{B r}_{2}$ display an additional longer wavelength emission band $\left(\lambda_{\max } \approx 500 \mathrm{~nm}\right)$ at temperatures of $120 \mathrm{~K}$ and higher, which strengthens upon continuous irradiation of the samples (Fig. S23 in the ESI $\dagger$ ). Similar spectral changes may also take place for $[8,10] \cdot \mathbf{B r}_{2}$, being less apparent due to the broad emission bands of these complexes. The appearance of the new emission bands can be tentatively attributed to the 


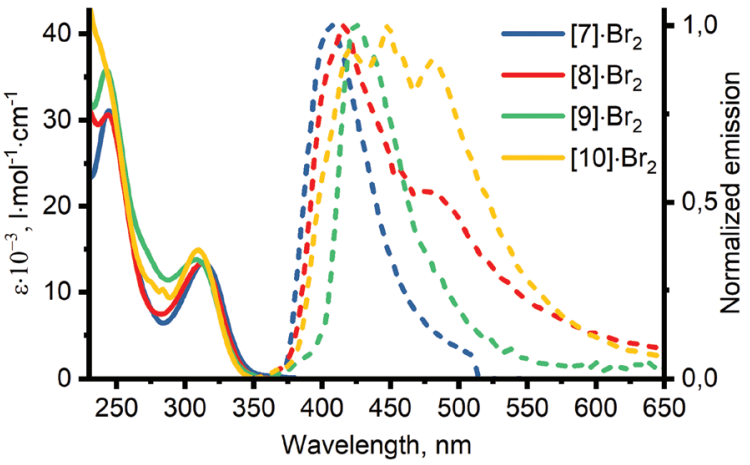

Fig. 6 Absorption (methanol solution, RT, solid lines) and phosphorescence emission (methanol/ethanol matrix, $80 \mathrm{~K}$, dashed lines) spectra of [7-10] $\mathrm{Br}_{2}(C=20 \mu \mathrm{M})$. Emission spectra were measured under excitation at $\lambda_{\mathrm{ex}}=320 \mathrm{~nm}$, delay $20 \mathrm{~ns}$, gate $10 \mu \mathrm{s}(30 \mu \mathrm{s}$ for $\left.[8] \cdot \mathrm{Br}_{2}\right)$.

Table 2 Absorption (methanol solution, RT) and phosphorescence emission (methanol/ethanol matrix, $80 \mathrm{~K}, \lambda_{\mathrm{ex}}=320 \mathrm{~nm}$ ) properties of $[7-10] \cdot \mathrm{Br}_{2}$

\begin{tabular}{|c|c|c|c|c|c|}
\hline Complex & $\lambda_{\mathrm{abs}}, \mathrm{nm}$ & $\varepsilon 10^{-3}, 1 \mathrm{~mol}^{-1} \mathrm{~cm}^{-1}$ & $\lambda_{\mathrm{em}}, \mathrm{nm}$ & $\tau_{1}, \mu \mathrm{s}$ & $\tau_{2}, \mu \mathrm{s}$ \\
\hline \multirow[t]{2}{*}[7]{$\cdot \mathrm{Br}_{2}$} & 244 & 31.0 & 407 & $78 \pm 4$ & $200 \pm 3$ \\
\hline & 313 & 13.4 & & & \\
\hline \multirow[t]{2}{*}[8]{$\cdot \mathrm{Br}_{2}$} & 244 & 30.6 & 417 & $\leq 6^{b}$ & $39 \pm 1$ \\
\hline & 312 & 13.3 & $470 / 500^{a}$ & $\leq 90^{b}$ & $3700 \pm 60^{c}$ \\
\hline \multirow[t]{2}{*}[9]{$\cdot \mathrm{Br}_{2}$} & 243 & 35.8 & 425 & $\leq 5^{b}$ & $45 \pm 1$ \\
\hline & 308 & 13.8 & & & \\
\hline \multirow[t]{2}{*}[10]{$\cdot \mathrm{Br}_{2}$} & 240 & 37.6 & $422 / 448 / 480^{a}$ & $21 \pm 1$ & $160 \pm 20$ \\
\hline & 310 & 14.9 & & & \\
\hline
\end{tabular}

${ }^{a}$ Bands with multiple local maxima. ${ }^{b}$ Lifetimes too short for reliable determination using the applied gate times. ${ }^{c}$ Measured at an equilibrium state, since the sample was excited by the laser at $100 \mathrm{~Hz}$ pulse repetition rate. Therefore, the real value may be slightly lower.

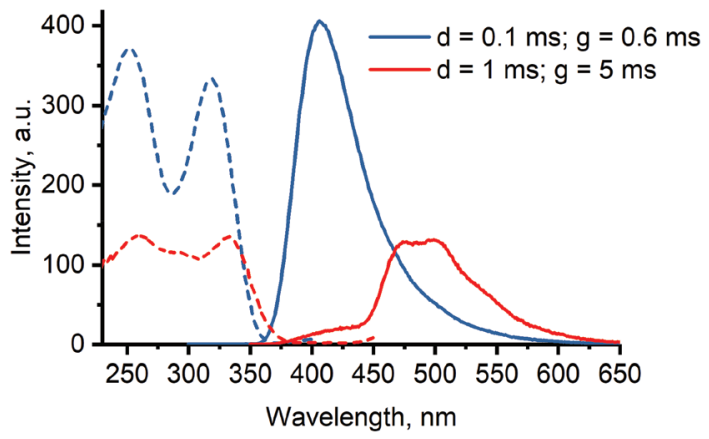

Fig. 7 Phosphorescence excitation (dashed lines, monitored at emission maximum) and emission (solid lines, monitored at excitation maximum) spectra of [8] $\cdot \mathrm{Br}_{2}$ in methanol/ethanol glass under two sets of timing parameters ( $77 \mathrm{~K}, \mathrm{C}=20 \mu \mathrm{M}, \mathrm{d}=$ delay, $\mathrm{g}=$ gate).

formation of excimers in viscous methanol/ethanol solution at higher temperatures, which is a common feature of platinum(II) complexes. $^{43}$
Summarizing, the obtained complexes $[\mathbf{7 - 1 0}] \cdot \mathbf{B r}_{2}$ demonstrate generally similar absorption and phosphorescence spectra with excited state lifetimes of microsecond order, typical for platinum(II) complexes. ${ }^{43}$ On the other hand, the exceptionally long lifetime of the second emission band of [8] $\cdot \mathbf{B r}_{2}$ - a unique feature of among the obtained complexes is quite intriguing. This emission does not seem to originate either from excimer formation or from aggregation, since it is present in frozen matrix at $77 \mathrm{~K}$, and does not depend on concentration (Fig. S11-18 in the ESI $\dagger$ ). Thus, the additional green emission of [8] $\cdot \mathbf{B r}_{2}$ can be supposedly associated with a specific conformation of the complex in the excited state, stabilized by an intramolecular interaction involving iodine atoms. Further studies of conformational flexibility and its impact on photophysical properties of $\mathbf{8}$ are currently being conducted in our research group.

\section{Conclusions}

Reaction between substituted benzyl bromides and [Pt(dpa$\mathrm{H})_{2}$ ] is demonstrated to be an efficient synthetic route towards benzyldi(2-pyridyl)amine complexes of platinum(II), which can serve as an example of the proposed non-conventional approach towards synthesis of metal complexes with methylene bridged dpa derivatives. This approach involves derivatization as the last step, when the dpa moiety is already coordinated on metal center, therefore allowing efficient onestep synthesis of multiple complexes and at the same time preventing undesired side reactions. The compounds obtained in this work possess conformational flexibility due to the methylene bridge, which results in various orientations of the substituents in solid state. The complexes are not emissive in solution at room temperature, but display blue and green phosphorescence in frozen methanol/ethanol matrix at $77 \mathrm{~K}$ with the lifetimes of $\mu$ s order. The iodine substituted complex 8 possesses additional green emission with the lifetime of about 3.7 ms. Further studies on complex 8 and origin of its dual emission are underway.

\section{Experimental}

All reagents and solvents for syntheses were purchased from Sigma-Aldrich, except for $\mathrm{K}_{2} \mathrm{PtCl}_{4}$ (Strem Chemicals and Alfa Aesar), and used as received without further purification. ${ }^{1} \mathrm{H}$ NMR spectra were recorded using Bruker Avance III HD $300 \mathrm{MHz}$ and Bruker Avance $400 \mathrm{MHz}$ spectrometers. Chemical shifts are expressed in ppm using residual solvent peak as internal standard. All the obtained ${ }^{1} \mathrm{H}$ NMR spectra are presented in section S5 in the ESI. $\dagger$ Elemental analyses (C, $\mathrm{H}, \mathrm{N})$ were preformed using Elementar Vario EL III elemental analyzer. Electrospray ionization mass spectra (ESI MS) were obtained with a Bruker micrOTOF or Agilent 6560 LC-IMMS TOF spectrometers equipped with an ESI source using methanol or acetonitrile as solvents. 


\section{Crystallography}

The crystals of 1-10 and S2-4 were immersed in cryo-oil, mounted in a MiTeGen loop and measured at $120 \mathrm{~K}$ on a Rigaku Oxford Diffraction Supernova diffractometer or at $170 \mathrm{~K}$ on a Bruker Axs KappaApexII diffractometer using Mo $\mathrm{K} \alpha(\lambda=0.71073)$ radiation. The CrysAlisPro ${ }^{46}$ or DenzoScalepack ${ }^{47}$ program packages were used for cell refinements and data reductions. Multi-scan/Gaussian/Analytical absorption correction (CrysAlisPro, ${ }^{46} \mathrm{SADABS}^{48}$ ) was applied to the intensities before structure solution. The structures were solved by intrinsic phasing method using the SHELXT ${ }^{49}$ software. Structural refinements were carried out using Olex ${ }^{50}$ graphical user interface. Intrinsic disorder was modelled over two positions for one of the nitro groups in 3 and for 2-iodobenzyl moiety in 5 and [8].(OTf) $)_{2}$. C-H and O-H hydrogen atoms were positioned geometrically and constrained to ride on their parent atoms, with $\mathrm{C}-\mathrm{H}=0.95-1.00 \AA$, $\mathrm{O}-\mathrm{H}=0.85 \AA$, and $U_{\text {iso }}=1.2-1.5 U_{\text {eq }}$ (parent atom), except for [10]-(OTf $)_{2}$, in which the $\mathrm{H}_{2} \mathrm{O}$ hydrogen atoms were located from the difference Fourier and refined isotropically. The crystallographic details are summarized in section S6 in the ESI. $\dagger$

\section{Optical spectroscopy}

HPLC grade methanol (J.T. Baker) and Uvasolv grade ethanol (Sigma-Aldrich) were used as solvents for optical measurements. Absorption spectra of $\mathbf{1 - 3}$ and $[\mathbf{7 - 1 0}] \cdot \mathbf{B r}_{2}$ were measured at ambient temperature in $\mathrm{MeOH}$ solution on Varian Cary 100 UV-visible spectrophotometer using quartz cuvettes with $1 \mathrm{~cm}$ path length in range of 220-700 $\mathrm{nm}$. Steady state phosphorescence excitation and emission spectra of [7-10] $\cdot \mathrm{Br}_{2}$ at $77 \mathrm{~K}$ in $\mathrm{MeOH} / \mathrm{EtOH}(1: 4, \mathrm{v} / \mathrm{v})$ solution (presented in Fig. 7 and S6†) were measured on Varian Cary Eclipse Fluorescence spectrophotometer equipped with Oxford Optistat cryostat using cryogenic $1 \mathrm{~cm}$ quartz luminescence cuvette (FireflySci). Delay and gate times were adjusted in ranges of $0.1-1 \mathrm{~ms}$ and $0.6-5 \mathrm{~ms}$ accordingly using functions implemented in the spectrophotometer.

Phosphorescence emission decays were measured using the stroboscopic time resolution technique. ${ }^{51}$ Samples were excited at $\lambda_{\text {ex }}=320 \mathrm{~nm}$ with $5 \mathrm{~ns}$ pulses $(100 \mathrm{~Hz}$ repetition rate) using the diode pumped Q-switched Nd:YAG laser Ekspla NL230-100 with integrated optical parametric oscillator. The phosphorescence emission was detected at $90^{\circ}$ angle using Oriel InstaSpec V ICCD detector with Acton SpectraPro sp-150i Spectrograph equipped with 300 grooves per mm grating blazed at $500 \mathrm{~nm}$. Stanford Research Systems digital delay generator DG535 was used for controlling delay and gate timing parameters. Temperature of the samples was controlled within 80-150 K range using Oxford Optistat cryostat with nitrogen as static heat exchange gas. Sample solutions were placed in cryogenic $1 \mathrm{~cm}$ quartz luminescence cuvette (FireflySci) and deaerated by bubbling nitrogen gas for 10 minutes prior to measurements. A mechanical shutter was used to block the excitation beam between measurements to avoid photoinduced changes in the samples. The obtained spectra were processed using
OriginPro software. The lifetime values were determined from the slopes of the fitted linear $\ln (I)$ vs. delay functions (see section S4 in the ESI†).

\section{Synthetic procedures}

Synthesis of benzyldi(2-pyridyl)amine (1). The product was synthesized according to published procedure. ${ }^{22}$ Solution of benzyl bromide (190 mg, $1.1 \mathrm{mmol})$ in DMF (3 ml) was added to suspension of dpa (171 mg, $1 \mathrm{mmol}$ ) and sodium hydroxide (160 mg, $4 \mathrm{mmol}$ ) in DMF $(5 \mathrm{ml})$ at room temperature. The mixture was stirred at $75{ }^{\circ} \mathrm{C}$ for $24 \mathrm{~h}$ to change color from yellowish to brown-orange. The solvent was evaporated on rotary evaporator and the residue was dissolved in mixture of water $(15 \mathrm{ml})$ and chloroform $(15 \mathrm{ml})$. Water phase was separated and extracted with chloroform $(2 \times 15 \mathrm{ml})$. The combined organic extract was dried over $\mathrm{Na}_{2} \mathrm{SO}_{4}$, filtered and evaporated. The residue was subjected to column chromatography purification on silica gel using chloroform/methanol $(5: 1, \mathrm{v} / \mathrm{v})$ mixture as eluent. Product containing fractions were combined and evaporated to give yellow powder, which was recrystallized from acetone to obtain colorless crystals of the product (68 mg, 26\%). Elemental analysis (\%): C, 77.6; H, 5.4; N, 16.1. Calc. for $\mathrm{C}_{17} \mathrm{H}_{15} \mathrm{~N}_{3}$ : C, 78.1; H, 5.8; N, 16.1. ${ }^{1} \mathrm{H}$ NMR (acetone$d 6,400 \mathrm{MHz}): \delta$ 8.29-8.25 (m, 2H), 7.63-7.57 (m, 2H), 7.38-7.34 (m, 2H), 7.27-7.20 (m, 4H), 7.16-7.12 (m, 1H), 6.92-6.87 (m, 2H), $5.53\left(\mathrm{~s}, 2 \mathrm{H}, \mathrm{CH}_{2}\right)$. ESI MS $(\mathrm{m} / \mathrm{z}): 262.14$ (calcd for $[\mathrm{M}+\mathrm{H}]^{+}$262.13), 545.26 (calcd for $[2 \mathrm{M}+\mathrm{Na}]^{+}$ 545.24). Crystals suitable for X-ray diffraction analysis were obtained by slow evaporation of solution in acetone.

Synthesis of 2-iodobenzyldi(2-pyridyl)amine (2). Solution of 2 -iodobenzyl bromide (600 $\mathrm{mg}, 2 \mathrm{mmol}$ ) in DMF (3 ml) was added to suspension of dpa (342 $\mathrm{mg}, 2 \mathrm{mmol})$ and sodium hydroxide $(240 \mathrm{mg}, 6 \mathrm{mmol})$ in DMF $(5 \mathrm{ml})$. The resulted mixture was stirred at room temperature for $24 \mathrm{~h}$ to change color from yellowish to dark-yellow. Remaining solids of sodium hydroxide were filtered and solvent was evaporated on rotary evaporator. Brown residue was dissolved in mixture of water $(20 \mathrm{ml})$ and chloroform $(20 \mathrm{ml})$. Water phase was separated and extracted with chloroform $(3 \times 20 \mathrm{ml})$. Combined organic extracts were dried over $\mathrm{Na}_{2} \mathrm{SO}_{4}$, filtered and evaporated to volume of $20 \mathrm{ml}$. Acetone $(20 \mathrm{ml})$ was added and the solution was left overnight at $5{ }^{\circ} \mathrm{C}$ for crystallization. Obtained yellowish crystals were filtered, washed with acetone $(2 \times 2 \mathrm{ml})$, and recrystallized from acetone/chloroform $(1: 1, \mathrm{v} / \mathrm{v})$ solution to obtain the product as colorless crystals (345 mg, 44\%). Elemental analysis (\%): C, 52.6; H, 3.4; N, 10.9. Calcd for $\mathrm{C}_{17} \mathrm{H}_{14} \mathrm{~N}_{3} \mathrm{I}$ : C, 52.7; H, 3.6; N, 10.9. ${ }^{1} \mathrm{H} \mathrm{NMR}\left(\mathrm{CDCl}_{3}, 300 \mathrm{MHz}\right)$ : $\delta$ 8.31-8.29 (m, 2H), $7.83(\mathrm{dd}, 1 \mathrm{H}, J=1.0,7.9 \mathrm{~Hz}), 7.58-7.50$ $(\mathrm{m}, 2 \mathrm{H}), 7.25-7.15(\mathrm{~m}, 4 \mathrm{H}), 6.93-6.83(\mathrm{~m}, 3 \mathrm{H}), 5.41(\mathrm{~s}, 2 \mathrm{H}$, $\mathrm{CH}_{2}$ ). ESI MS $(\mathrm{m} / \mathrm{z}): 387.99$ (calcd for $[\mathrm{M}+\mathrm{H}]^{+}$388.03). Crystals suitable for X-ray diffraction analysis were obtained by slow evaporation of solution in chloroform.

Synthesis of 2-nitrobenzyldi(2-pyridyl)amine (3). Synthesis was conducted under nitrogen atmosphere using standard Schlenk techniques similarly to published procedure. ${ }^{38}$ Sodium hydride (290 mg, 60\% in mineral oil, $7.25 \mathrm{mmol}$ ) was 
mixed with pentane $(20 \mathrm{ml})$ and resulted suspension stirred for $3 \mathrm{~min}$. When solids settled down most of the solvent was decanted to remove the oil. The procedure was repeated once more and remaining pentane was dried out under vacuum. Toluene $(5 \mathrm{ml})$ was added with stirring at $-78{ }^{\circ} \mathrm{C}$ followed by solution of dpa $(860 \mathrm{mg}, 5.03 \mathrm{mmol})$ in toluene $(20 \mathrm{ml})$. The reaction mixture was allowed to heat up to room temperature. During this time formation of gas bubbles and cream colored precipitate was observed. The mixture was stirred for $1 \mathrm{~h}$ at room temperature (stirring was hampered due to formation of precipitate) and $18 \mathrm{~h}$ at $100{ }^{\circ} \mathrm{C}$. After cooling to room temperature, solution of 2-nitrobenzyl bromide $(1.3 \mathrm{~g}, 6.02 \mathrm{mmol})$ in toluene $(20 \mathrm{ml})$ was added to the resulted gray suspension. The mixture was stirred at room temperature for $30 \mathrm{~min}$ and then at $100{ }^{\circ} \mathrm{C}$ overnight. After cooling to room temperature formed light brown precipitate was filtered; brown filtrate was concentrated on rotary evaporator. The obtained brown oil was dissolved in chloroform, filtered from formed white precipitate (side product S3, see section S1 in the ESI + ), and solution subjected to column chromatography purification using chloroform/diethyl ether $(1: 1, \mathrm{v} / \mathrm{v})$ mixture as eluent. Product containing fractions were combined and subjected to second column chromatography purification using ethyl acetate/ hexane $(1: 5 \rightarrow 3: 5, \mathrm{v} / \mathrm{v})$ mixture as eluent. Product containing fractions were combined and slowly evaporated at room temperature to produce yellow crystals, which were recrystallized from ethyl acetate/pentane/diethyl ether $(1: 2: 1, \mathrm{v} / \mathrm{v})$ solution to get the product as yellowish crystals (137 mg, 9\%). Elemental analysis (\%): C, 66.3; H, 4.3; N, 18.05. Calcd for $\mathrm{C}_{17} \mathrm{H}_{14} \mathrm{~N}_{4} \mathrm{O}_{2}$ : C, 66.7; $\mathrm{H}, 4.6 ; \mathrm{N}, 18.3$. ${ }^{1} \mathrm{H}$ NMR $\left(\mathrm{CDCl}_{3}\right.$, $300 \mathrm{MHz}): \delta 8.29-8.27(\mathrm{~m}, 2 \mathrm{H}), 8.04(\mathrm{dd}, 1 \mathrm{H}, J=1.3,8.0 \mathrm{~Hz})$, 7.60-7.50 (m, 3H), 7.48-7.41 (m, 1H), 7.36-7.29 (m, 1H), 7.24-7.19 (m, 2H), 6.89-6.84 (m, 2H), $5.83\left(\mathrm{~s}, 2 \mathrm{H}, \mathrm{CH}_{2}\right)$. ESI MS $\left(\mathrm{m} / \mathrm{z}\right.$ ): 307.11 (calcd for $[\mathbf{M}+\mathbf{H}]^{+}$307.12). Crystals suitable for $\mathrm{X}$-ray diffraction analysis were obtained by slow evaporation of solution in ethyl acetate/pentane/diethyl ether $(1: 2: 1, \mathrm{v} / \mathrm{v})$.

Synthesis of diiodo(benzyldi(2-pyridyl)amine)platinum(II) (4). Solution of $\mathrm{K}_{2} \mathrm{PtCl}_{4}(62 \mathrm{mg}, 0.15 \mathrm{mmol})$ and $\mathrm{KI}(620 \mathrm{mg}$, $3.73 \mathrm{mmol})$ in water $(10 \mathrm{ml})$ was stirred for $20 \mathrm{~min}$. Solid 1 (45 $\mathrm{mg}, 0.17 \mathrm{mmol}$ ) was added to the obtained dark-red solution and the resulting suspension was stirred for $19 \mathrm{~h}$ at room temperature and then $30 \mathrm{~min}$ at $85^{\circ} \mathrm{C}$. Yellow precipitate was filtered out and washed with chloroform $(5 \times 1 \mathrm{ml})$ to give the product as yellow powder $(87.3 \mathrm{mg}, 82 \%)$. Elemental analysis (\%): C, 28.6; H, 2.2; N, 6.1. Calcd for $\mathrm{C}_{17} \mathrm{H}_{15} \mathrm{~N}_{3} \mathrm{I}_{2} \mathrm{Pt}: \mathrm{C}, 28.8 ; \mathrm{H}$, 2.1; N, 5.9. ${ }^{1} \mathrm{H}$ NMR (THF- $\left.d 8,400 \mathrm{MHz}\right): \delta 9.45-9.29(\mathrm{~m}, 2 \mathrm{H}$, broad sidebands due to $\left.{ }^{3} J_{\mathrm{Pt}, \mathrm{H}}=45.0 \mathrm{~Hz}\right), 7.93-7.87(\mathrm{~m}, 2 \mathrm{H})$, 7.84-7.79 (m, 2H), 7.38-7.27 (m, 4H), 7.18 (m, 1H), 7.11-7.06 $(\mathrm{m}, 2 \mathrm{H}), 5.37\left(\mathrm{~s}, 2 \mathrm{H}, \mathrm{CH}_{2}\right)$. ESI MS $(\mathrm{m} / \mathrm{z}): 624.00$ (calcd for $\left[\mathrm{M}-\mathrm{I}+\mathrm{CH}_{3} \mathrm{CN}\right]^{+}$624.02), 262.12 (calcd for $\left[\mathrm{M}-\mathrm{PtI}_{2}+\mathrm{H}\right]^{+}$ 262.13). Crystals suitable for X-ray diffraction analysis were obtained by slow evaporation of solution in THF.

Synthesis of diiodo(2-iodobenzyldi(2-pyridyl)amine)platinum(II) (5). Solution of $\mathrm{K}_{2} \mathrm{PtCl}_{4}(124 \mathrm{mg}, 0.30 \mathrm{mmol})$ and $\mathrm{KI}(1.25 \mathrm{~g}$, $7.5 \mathrm{mmol})$ in water/THF mixture $(10 \mathrm{ml}, 1: 1, \mathrm{v} / \mathrm{v})$ was stirred for $20 \mathrm{~min}$. Solid $2(120 \mathrm{mg}, 0.31 \mathrm{mmol})$ was added to the obtained dark-red solution and the resulting suspension was refluxed for $16 \mathrm{~h}$ at $85{ }^{\circ} \mathrm{C}$. The solvent was partly evaporated on rotary evaporator and yellow-orange powder was filtered and washed with chloroform $(5 \times 3 \mathrm{ml})$ and THF $(5 \times 3 \mathrm{ml})$ to give the product as yellow powder $(120.4 \mathrm{mg}, 48 \%)$. Elemental analysis (\%): C, 24.3; H, 1.7; N, 4.9. Calcd for $\mathrm{C}_{17} \mathrm{H}_{14} \mathrm{~N}_{3} \mathrm{I}_{3} \mathrm{Pt}$ : C, 24.4; H, 1.7; N, 5.0. ${ }^{1} \mathrm{H}$ NMR (THF- $\left.d 8,300 \mathrm{MHz}\right): \delta 9.49-9.29$ $\left(\mathrm{m}, 2 \mathrm{H}\right.$, broad sidebands due to $\left.{ }^{3} J_{\mathrm{Pt}, \mathrm{H}}=46.3 \mathrm{~Hz}\right), 8.40(\mathrm{~d}, 1 \mathrm{H}$, $J=7.9 \mathrm{~Hz}), 7.99-7.92(\mathrm{~m}, 2 \mathrm{H}), 7.84(\mathrm{dd}, 1 \mathrm{H}, J=1.4,7.9 \mathrm{~Hz})$, 7.70-7.30 (m, 3H), 7.16-7.08 (m, 2H), 6.99-6.91 (m, 1H), 5.43 $\left(\mathrm{s}, 2 \mathrm{H}, \mathrm{CH}_{2}\right.$ ). ESI MS $(\mathrm{m} / \mathrm{z}): 749.89$ (calcd for $\left[\mathrm{M}-\mathrm{I}+\mathrm{CH}_{3} \mathrm{CN}\right]^{+}$ 749.91). Crystals suitable for X-ray diffraction analysis were obtained by slow evaporation of solution in THF.

Synthesis of diiodo(2-nitrobenzyldi(2-pyridyl)amine)platinum(II) (6). Solution of $\mathrm{K}_{2} \mathrm{PtCl}_{4}(61 \mathrm{mg}, 0.15 \mathrm{mmol})$ and $\mathrm{KI}$ (610 $\mathrm{mg}, 3.67 \mathrm{mmol})$ in water $(10 \mathrm{ml})$ was stirred for $20 \mathrm{~min}$. Solution of 3 ( $45 \mathrm{mg}, 0.15 \mathrm{mmol})$ in THF $(4 \mathrm{ml})$ was added to the obtained dark-red solution and the resulting suspension was stirred for $20 \mathrm{~h}$ at $70{ }^{\circ} \mathrm{C}$. The solvent was partly evaporated on rotary evaporator and brown precipitate was filtered and washed with water $(3 \mathrm{ml})$. Resulting solids were suspended in boiling chloroform $(7 \mathrm{ml})$ and yellow solution was decanted. The procedure was repeated 5 times, the obtained solutions were combined and evaporated. The residue was washed with chloroform $(2 \times 2 \mathrm{ml})$ and suspended in THF $(3 \mathrm{ml})$. Dark solution was decanted and brown-yellow solids were washed with THF $(3 \times 1 \mathrm{ml})$ and chloroform $(2 \times 1 \mathrm{ml})$ to give the product as yellow powder $(23 \mathrm{mg}, 20 \%)$. Elemental analysis (\%): $\mathrm{C}, \quad 26.8 ; \mathrm{H}, \quad 1.8 ; \quad \mathrm{N}, \quad 7.4$. Calcd for $\mathrm{C}_{17} \mathrm{H}_{14} \mathrm{~N}_{4} \mathrm{O}_{2} \mathrm{I}_{2}$ Pt: C, 27.0; H, 1.8; N, 7.4. ${ }^{1} \mathrm{H}$ NMR (THF- $d 8$, $300 \mathrm{MHz}): \delta 9.48-9.29(\mathrm{~m}, 2 \mathrm{H}$, broad sidebands due to $\left.{ }^{3} J_{\mathrm{Pt}, \mathrm{H}}=44.4 \mathrm{~Hz}\right), 9.02(\mathrm{~d}, 1 \mathrm{H}, J=7.7 \mathrm{~Hz}), 8.04(\mathrm{dd}, 1 \mathrm{H}, J=1.1$, $8.1 \mathrm{~Hz}), 8.00-7.90(\mathrm{~m}, 2 \mathrm{H}), 7.71-7.62(\mathrm{~m}, 1 \mathrm{H}), 7.56-7.40(\mathrm{~m}$, $2 \mathrm{H}), 7.19-7.10(\mathrm{~m}, 1 \mathrm{H}), 5.81\left(\mathrm{~s}, 2 \mathrm{H}, \mathrm{CH}_{2}\right)$. ESI MS $(\mathrm{m} / \mathrm{z})$ : 668.78 (calcd for $\left[\mathrm{M}-\mathrm{I}+\mathrm{CH}_{3} \mathrm{CN}\right]^{+}$669.00). Crystals suitable for X-ray diffraction analysis were obtained by slow evaporation of solution in THF.

General procedure for conventional synthesis of bis(benzyldi (2-pyridyl)amine)platinum(II) triflate complexes [7-9].(OTf) $)_{2}$

Suspension of precursor complex 4-6 $(0.1 \mathrm{mmol})$ and corresponding ligand 1-3 $(0.1 \mathrm{mmol})$ in acetonitrile $(10 \mathrm{ml})$ was stirred at $60{ }^{\circ} \mathrm{C}$ for $10 \mathrm{~min}$. Solution of silver triflate $(55 \mathrm{mg}$, $0.21 \mathrm{mmol})$ in acetonitrile $(5 \mathrm{ml})$ was added dropwise at this temperature within 5-7 min. Resulted mixture was stirred in darkness at $75{ }^{\circ} \mathrm{C}$ for $16 \mathrm{~h}$. Yellow precipitate of silver iodide was filtered off and the filtrate was partially evaporated on rotary evaporator to volume of $2 \mathrm{ml}$ and allowed to evaporate slowly at room temperature overnight. Resulted crystals were washed with THF $(2 \times 2 \mathrm{ml})$, recrystallized from methanol/ acetonitrile mixture $(1: 1, \mathrm{v} / \mathrm{v})$, and washed again with THF $(3 \times 2 \mathrm{ml})$ to give product as colorless crystals. Crystals of $[7,8] \cdot(\text { OTf })_{2}$ suitable for X-ray diffraction analysis were obtained by slow evaporation of solution in methanol. No high quality crystals could be obtained for [9].(OTf $)_{2}$, and crystals of [9]· $\mathbf{B r}_{2}$ were measured instead. 
Bis(benzyldi(2-pyridyl)amine)platinum(II) triflate ([7]-(OTf) $)_{2}$. Yield: $14 \mathrm{mg}, 14 \%$. Elemental analysis (\%): C, 42.0; H, 2.7; N, 8.0. Calcd for $\mathrm{C}_{36} \mathrm{H}_{30} \mathrm{~N}_{6} \mathrm{O}_{6} \mathrm{~F}_{6} \mathrm{~S}_{2} \mathrm{Pt}$ : C, 42.6; H, 3.0; N, 8.3. ${ }^{1} \mathrm{H}$ NMR ( $\left.\mathrm{CD}_{3} \mathrm{CN}, 400 \mathrm{MHz}\right): \delta 8.14-8.08(\mathrm{~m}, 4 \mathrm{H}), 7.85(\mathrm{~d}, 4 \mathrm{H}, J=$ $7.1 \mathrm{~Hz}), 7.78-7.68(\mathrm{~m}, 8 \mathrm{H}), 7.44-7.37(\mathrm{~m}, 4 \mathrm{H}), 7.36-7.30(\mathrm{~m}$, $2 \mathrm{H}), 7.22-7.17(\mathrm{~m}, 4 \mathrm{H}), 5.51\left(\mathrm{~s}, 4 \mathrm{H}, \mathrm{CH}_{2}\right)$. ESI MS (m/z): 866.13 (calcd for $[\mathrm{M}-\mathrm{OTf}]^{+}$866.17).

Bis(2-iodobenzyldi(2-pyridyl)amine)platinum(II) triflate ([8].(OTf $)_{2}$ ). Yield: $83 \mathrm{mg}, 61 \%$. Elemental analysis (\%): C, 34.1; H, 2.1; N, 6.75. Calcd for $\mathrm{C}_{36} \mathrm{H}_{28} \mathrm{~N}_{6} \mathrm{O}_{6} \mathrm{~F}_{6} \mathrm{~S}_{2} \mathrm{I}_{2}$ Pt: C, 34.1; $\mathrm{H}$, 2.2; N, 6.6. ${ }^{1} \mathrm{H}$ NMR ( $\left.\mathrm{CD}_{3} \mathrm{OD}, 300 \mathrm{MHz}\right): \delta 8.28-8.20(\mathrm{~m}, 4 \mathrm{H})$, 7.98-7.88 (m, 8H), 7.77 (m, 4H), 7.50-7.42 (m, 2H), 7.32-7.25 $(\mathrm{m}, 4 \mathrm{H}), 7.15-7.08(\mathrm{~m}, 2 \mathrm{H}), 5.57\left(\mathrm{~s}, 4 \mathrm{H}, \mathrm{CH}_{2}\right)$. ESI MS $(\mathrm{m} / \mathrm{z})$ : 1117.92 (calcd for $[\mathrm{M}-\mathrm{OTf}]^{+} 1117.96$ ).

Bis(2-nitrobenzyldi(2-pyridyl)amine)platinum(II) triflate ([9].(OTf $)_{2}$ ). Yield: $17 \mathrm{mg}, 15 \%$. Elemental analysis (\%): C, 39.1; H, 2.6; N, 9.7. Calcd for $\mathrm{C}_{36} \mathrm{H}_{28} \mathrm{~N}_{8} \mathrm{O}_{10} \mathrm{~F}_{6} \mathrm{~S}_{2} \mathrm{Pt}$ : C, 39.1; $\mathrm{H}$, 2.55; N, 10.1. ${ }^{1} \mathrm{H}$ NMR ( $\left.\mathrm{CD}_{3} \mathrm{OD}, 300 \mathrm{MHz}\right): \delta 8.30-8.22(\mathrm{~m}, 4 \mathrm{H})$, 8.04-7.92 (m, 8H), 7.84-7.72 (m, 6H), 7.68-7.61 (m, 2H), 7.38-7.31 (m, 4H), $5.91\left(\mathrm{~s}, 4 \mathrm{H}, \mathrm{CH}_{2}\right)$. ESI MS $(\mathrm{m} / \mathrm{z}): 403.59$ (calcd for $[\mathrm{M}-2 \mathrm{OTf}]^{2+}$ 403.59).

General procedure for alternative synthesis of bis(benzyldi(2pyridyl)amine)platinum(II) bromide complexes [7-10] $\cdot \mathrm{Br}_{2}$

[Pt(dpa-H) $)_{2}$ (53 mg, $0.1 \mathrm{mmol}$, prepared according to previously published procedure ${ }^{33}$ with $38 \%$ yield) and corresponding benzyl bromide $(0.2 \mathrm{mmol})$ were suspended in acetonitrile $(20 \mathrm{ml})$ and stirred at $75{ }^{\circ} \mathrm{C}$ for $24 \mathrm{~h}$ and refluxed for $2 \mathrm{~h}$. Solvent was evaporated on rotary evaporator, and yellow residue was washed with chloroform $(2 \times 2 \mathrm{ml})$ and diethyl ether $(2 \times 2 \mathrm{ml})$. Resulting colorless solids were recrystallized from methanol to afford product as colorless crystalline

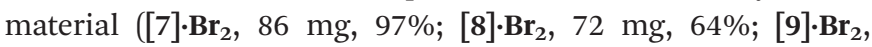
$82 \mathrm{mg}, 85 \%) .{ }^{1} \mathrm{H}$ NMR spectra of [7-9] $\cdot \mathbf{B r}_{2}$ matched those pre-

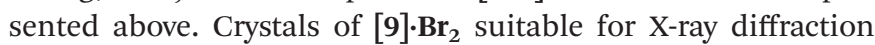
analysis were obtained by slow evaporation of solution in methanol. In synthesis of $[\mathbf{1 0}] \cdot \mathbf{B r}_{2}$, additional side product $\mathbf{S 4}$ was isolated and identified (see section S2 in the ESI $\dagger$ ).

Bis(2-cyanobenzyldi(2-pyridyl)amine)platinum(II) bromide $\left([10] \cdot \mathbf{B r}_{2}\right)$. Yield: $78 \mathrm{mg}, 79 \%$. Elemental analysis (\%): C, 46.2; $\mathrm{H}, 3.2 ; \mathrm{N}, 11.7$. Calcd for $\mathrm{C}_{36} \mathrm{H}_{28} \mathrm{~N}_{8} \mathrm{Br}_{2} \mathrm{Pt}$ : C, 46.6; $\mathrm{H}, 3.0 ; \mathrm{N}$, 12.1. ${ }^{1} \mathrm{H}$ NMR ( $\left.\mathrm{CD}_{3} \mathrm{OD}, 300 \mathrm{MHz}\right): \delta 8.30-8.22(\mathrm{~m}, 4 \mathrm{H})$, 8.07-8.02 (m, 2H), 7.97-7.95 (m, 4H) 7.88-7.72 (m, 8H), 7.60-7.54 (m, 2H), 7.33-7.27 (m, 2H), 5.75 (s, 4H, $\left.\mathrm{CH}_{2}\right)$. ESI MS $(\mathrm{m} / \mathrm{z}): 846.12$ (calcd for $[\mathrm{M}-\mathrm{Br}]^{+}$846.13), 383.60 (calcd for $\left.[\mathrm{M}-2 \mathrm{Br}]^{2+} 383.60\right)$. Since only poor quality thin needle crystals could be obtained from $[\mathbf{1 0}] \cdot \mathbf{B r}_{2}$, the reaction of anion exchange from bromide to triflate was performed using silver(I) triflate in methanol. Crystals of [10]-(OTf) $)_{2}$ suitable for $\mathrm{X}$-ray diffraction analysis were obtained by slow evaporation of the resulted filtered solution.

\section{Conflicts of interest}

There are no conflicts to declare.

\section{Acknowledgements}

E. B. and M. H. kindly acknowledge the financial support from the Academy of Finland (Proj. no. 295581). The authors would also like to acknowledge Elina Hautakangas for elemental analyses, Dr Elina Kalenius for mass spectrometry measurements, Dr Matti Tuikka for helping with X-ray analyses, and Dr Pasi Myllyperkiö and Dr Heikki Häkkänen for assisting with optical spectroscopy measurements.

\section{Notes and references}

1 D. W. Brogden and J. F. Berry, Comments Inorg. Chem., 2016, 36, 17-37.

2 C. J. Sumby, Coord. Chem. Rev., 2011, 255, 1937-1967.

3 B. Chen, G. Yu, X. Li, Y. Ding, C. Wang, Z. Liu and Y. Xie, J. Mater. Chem. C, 2013, 1, 7409-7417.

4 R. Tan, Z.-B. Wang, Y. Li, D. J. Kozera, Z.-H. Lu and D. Song, Inorg. Chem., 2012, 51, 7039-7049.

5 W.-L. Jia, T. McCormick, Q.-D. Liu, H. Fukutani, M. Motala, R.-Y. Wang, Y. Tao and S. Wang, J. Mater. Chem., 2004, 14, 3344-3350.

6 J. Pang, Y. Tao, S. Freiberg, X.-P. Yang, M. D'Iorio and S. Wang, J. Mater. Chem., 2002, 12, 206-212.

7 J. Pang, E. J.-P. Marcotte, C. Seward, R. S. Brown and S. Wang, Angew. Chem., Int. Ed., 2001, 40, 4042-4045.

8 Y.-Q. Weng, F. Yue, Y.-R. Zhong and B.-H. Ye, Inorg. Chem., 2007, 46, 7749-7755.

9 A. K. Paul, H. Mansuri-Torshizi, T. S. Srivastava, S. J. Chavan and M. P. Chitnis, J. Inorg. Biochem., 1993, 50, 9-20.

10 A. K. Paul, T. S. Srivastava, S. J. Chavan, M. P. Chitnis, S. Desai and K. K. Rao, J. Inorg. Biochem., 1996, 61, 179196.

11 C. Icsel, V. T. Yilmaz, Y. Kaya, H. Samli, W. T. A. Harrison and O. Buyukgungor, Dalton Trans., 2015, 44, 6880-6895.

12 M. J. Rauterkus, S. Fakih, C. Mock, I. Puscasu and B. Krebs, Inorg. Chim. Acta, 2003, 350, 355-365.

13 S. Fakih, W. C. Tung, D. Eierhoff, C. Mock and B. Krebs, Z. Anorg. Allg. Chem., 2005, 631, 1397-1402.

14 I. Puscasu, C. Mock, M. Rauterkus, A. Röndigs, G. Tallen, S. Gangopadhyay, J. E. Wolff and B. Krebs, Z. Anorg. Allg. Chem., 2001, 627, 1292-1298.

15 P. W. Asman, Inorg. Chim. Acta, 2018, 469, 341-352.

16 C. Seward and S. Wang, Comments Inorg. Chem., 2005, 26, 103-125.

17 Y. Kang and S. Wang, Tetrahedron Lett., 2002, 43, 37113713.

18 W.-L. Jia, D. Song and S. Wang, J. Org. Chem., 2003, 68, 701-705.

19 K.-J. Wei, Y.-S. Xie, J. Ni, M. Zhang and Q.-L. Liu, Inorg. Chem. Commun., 2006, 9, 926-930.

20 K.-J. Wei, Y.-S. Xie, J. Ni, M. Zhang and Q.-L. Liu, Cryst. Growth Des., 2006, 6, 1341-1350. 
21 J. Ni, K.-J. Wei, Y. Min, Y. Chen, S. Zhan, D. Li and Y. Liu, Dalton Trans., 2012, 41, 5280-5293.

22 B. Antonioli, D. J. Bray, J. K. Clegg, K. Gloe, K. Gloe, O. Kataeva, L. F. Lindoy, J. C. McMurtrie, P. J. Steel, C. J. Sumby and M. Wenzel, Dalton Trans., 2006, 47834794.

23 B. Antonioli, D. J. Bray, J. K. Clegg, K. Gloe, K. Gloe, A. Jäger, K. A. Jolliffe, O. Kataeva, L. F. Lindoy, P. J. Steel, C. J. Sumby and M. Wenzel, Polyhedron, 2008, 27, 28892898.

24 D. J. Bray, J. K. Clegg, K. A. Jolliffe and L. F. Lindoy, CrystEngComm, 2014, 16, 6476-6482.

25 P. W. Asman and D. Jaganyi, Int. J. Chem. Kinet., 2017, 49, 545-561.

26 J.-S. Yang, Y.-D. Lin, Y.-H. Chang and S.-S. Wang, J. Org. Chem., 2005, 70, 6066-6073.

27 M. A. Rohman, D. Sutradhar, S. Sangilipandi, K. Mohan Rao, A. K. Chandra and S. Mitra, J. Photochem. Photobiol., A, 2017, 341, 115-126.

28 A. J. Swarts and S. F. Mapolie, Dalton Trans., 2014, 43, 9892-9900.

29 M. Vaquero, A. Ruiz-Riaguas, M. Martínez-Alonso, F. A. Jalón, B. R. Manzano, A. M. Rodríguez, G. GarcíaHerbosa, A. Carbayo, B. García and G. Espino, Chem. - Eur. J., 2018, 24, 10662-10671.

30 J. F. Geldard and F. Lions, J. Am. Chem. Soc., 1962, 84, 2262-2263.

31 T. J. Hurley and M. A. Robinson, Inorg. Chem., 1968, 7, 33-38.

32 F. A. Cotton, L. M. Daniels, G. T. Jordan and C. A. Murillo, Polyhedron, 1998, 17, 589-597.

33 Q. Wang, P. V. Gushchin, N. A. Bokach, M. Haukka and V. Yu. Kukushkin, Russ. Chem. Bull., 2012, 61, 828-835.

34 Y. Tor, Synlett, 2002, 1043-1054.

35 T. Mede, M. Jäger and U. S. Schubert, Chem. Soc. Rev., 2018, 47, 7577-7627.
36 B. Minaev, G. Baryshnikov and H. Agren, Phys. Chem. Chem. Phys., 2014, 16, 1719-1758.

37 G. H. Sarova, N. A. Bokach, A. A. Fedorov, M. N. BerberanSantos, V. Yu. Kukushkin, M. Haukka, J. J. R. Frausto da Silva and A. J. L. Pombeiro, Dalton Trans., 2006, 3798-3805.

38 S. Licciulli, I. Thapa, K. Albahily, I. Korobkov, S. Gambarotta, R. Duchateau, R. Chevalier and K. Schuhen, Angew. Chem., Int. Ed., 2010, 49, 9225-9228.

39 V. M. Clark, A. Cox and E. J. Herbert, J. Chem. Soc. C, 1968, 831-833.

40 J. D. Cocker, G. I. Gregory and G. B. Webb, Br. Pat., GB 1262864, 1972.

41 E. Bulatov and M. Haukka, ChemistrySelect, 2018, 3, 1153511540.

42 K.-Y. Ho, W.-Y. Yu, K.-K. Cheung and C.-M. Che, J. Chem. Soc., Dalton Trans., 1999, 1581-1586.

43 J. A. G. Williams, Top. Curr. Chem., 2007, 281, 205-268.

44 D. R. Scott and J. B. Allison, J. Phys. Chem., 1962, 66, 561562.

45 T. O. Harju, J. E. I. Korppi-Tommola, A. H. Huizer and C. A. G. O. Varma, J. Phys. Chem., 1996, 100, 3592-3600.

46 Agilent, CrysAlisPro, Agilent Technologies Ltd, Yarnton, Oxfordshire, England, 2014.

47 Z. Otwinowski and E. Minor, in Methods in Enzymology, ed. C. W. Carter and R. M. Sweet, Academic Press, New York, 1997, vol. 276, Macromolecular Crystallography, Part A, pp. 307-326.

48 G. M. Sheldrick, SADABS - Bruker AXS, scaling and absorption correction, Bruker AXS, Inc., Madison, Wisconsin, USA, 2012.

49 G. M. Sheldrick, Acta Cryst. A, 2015, 71, 3-8.

50 O. V. Dolomanov, L. J. Bourhis, R. J. Gildea, J. A. K. Howard and H. Puschmann, J. Appl. Crystallogr., 2009, 42, 339-341.

51 D. R. James, A. Siemiarczuk and W. R. Ware, Rev. Sci. Instrum., 1992, 63, 1710-1716. 